\title{
Study on the Pollution Control of Down Washing Wastewater in West Anhui, China
}

\author{
Xinwei Song ${ }^{1, *}$, Yulan $\mathrm{Gao}^{1}$, Dongmei Shen ${ }^{1}$, Rusheng Jia ${ }^{1}$ \\ ${ }^{1}$ College of Architecture and Civil Engineering, West Anhui University, Luan, Anhui, China, 237012
}

\begin{abstract}
The down industry is one of the special agricultural industrial clusters in West Anhui province, China. There are large drainage and large pollution load in the washing down industry. By analysing the characteristics of wastewater from down washing industry, it is proposed that the enterprises of down industry should separate heavily polluted wastewater from slightly polluted and reuse the wastewater directly or after regeneration treatment. According to the gathering situation of down feather industrial enterprises in West Anhui province, it is proposed to build down feather industrial park and down specialized sewage treatment plant in the industrial gathering area, so as to solve the pollution problem of enterprises through centralized treatment and make industry bigger and stronger.
\end{abstract}

\section{Introduction}

Based on the excellent breed resources of the West Anhui white goose and unique geographical environment, the West Anhui region has established a deep processing system for down products, and it is "China export base of fine down products" and "national professional demonstration base of foreign trade transformation and upgrading" ${ }^{[1,2]}$. It has cultivated the down and feather industry cluster of Guzhen town and the down products cluster of Shucheng county ${ }^{[3]}$, which is one of the largest down export regions in China. The down industry is listed as one of the eight characteristic agricultural industrial clusters in Lu'an city, and it is proposed to establish the first-class down industry base in China ${ }^{[4]}$.

Down processing industry, especially washing down industry, consumes and discharges a large amount of water during the down products processing, and resulting a large pollution load ${ }^{[5,6]}$. With the implementation of the concept of ecological civilization construction and the normalization of environmental monitoring activities, the washed down industry is also facing environmental pressures. According to the information released on the website of the Lu'an municipal government, in the second half of 2018, the Lu'an municipal environmental authorities imposed administrative penalties on two washing down enterprises for allegedly discharging water pollutants in excess of national standards or operating sewage treatment equipment improperly. It is important to formulate a reasonable water pollutant control route for the washed down industry based on the agglomeration characteristics of the West Anhui down industry and the wastewater discharge characteristics of washed down enterprises.

\section{Contaminant characteristics of washed down water}

\subsection{Characteristics of down materials}

Down raw materials mainly come from duck, goose, which are gathered through brokers and professional markets. Among them, there are three ways to slaughter ducks and geese, including slaughtering in centralized slaughterhouses, slaughtering in town market and slaughtering by fur collectors going from village to village ${ }^{[7]}$.

Due to different feather collection methods, production seasons, goose and duck breeds, there are large differences in the quality of their raw materials. Soil, sand, and feces are adhered to the raw feather and down, and the quality varies greatly. The raw materials and down must be washed to meet garment requirements.

\section{2 pollutant emission characteristics}

In order to remove oil, dust, odour, etc. from feather down, raw materials (original down) need to be washed with water. During the washing process, special detergents and deodorants are added. After initial washing, washing and multiple rinsing, the feathers are cleaned $^{[5]}$. The flow chart of the down washing process in an enterprise is shown in Figure 1.

It can be seen from the production process flow chart in Figure 1 that the down industrial wastewater is mainly generated during the water washing (primary washing, cleaning, rinsing) process and the dewatering process. As the number of washings increases, the down becomes

\footnotetext{
* Corresponding author: 36650804@qq.com
} 
cleaner and the pollution degree of the discharged wastewater becomes less and less. The pollution load of primary washing wastewater is high, and the $\mathrm{COD}_{\text {cr }}$ can reach more than $1000 \mathrm{mg} / \mathrm{L}$. With the increase of washing times, the pollutants such as animal fat, protein and fine down in the raw plush and wastewater decrease gradually. In order to ensure the quality of down, the final rinsing wastewater need to meet the discharge standards and can be directly discharged or reused ${ }^{[5,6]}$. The water quality characteristics of typical down wastewater are shown in Table 1.

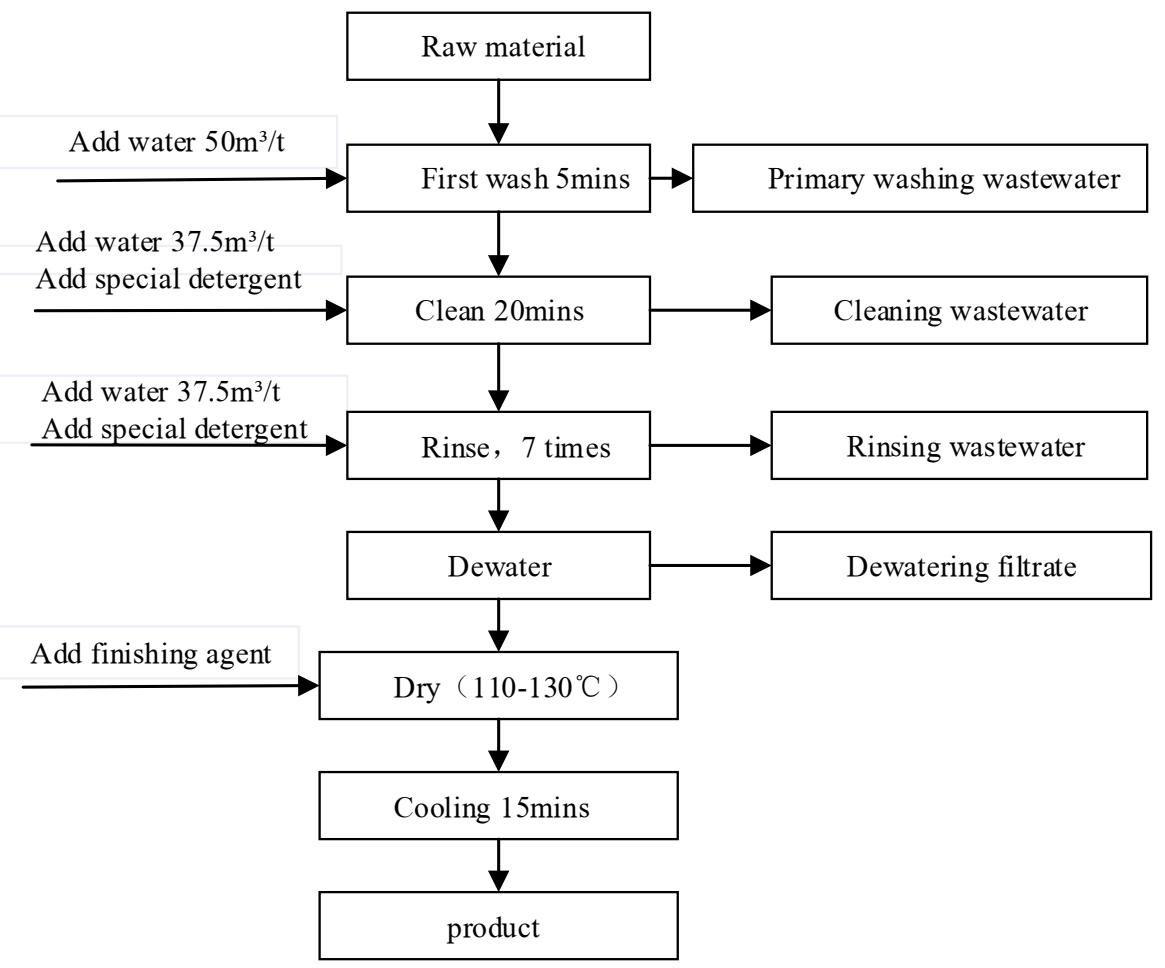

Fig. 1. Process flow diagram of washed down in an enterprise

Table 1. Discharge characteristics of typical pollutants from down wastewater

\begin{tabular}{cccccccc}
\hline Type of wastewater & $\begin{array}{c}\mathbf{C O D}_{\text {cr }} \\
(\mathbf{m g} / \mathbf{L})\end{array}$ & $\begin{array}{c}\mathbf{B O D}_{5} \\
(\mathbf{m g} / \mathbf{L})\end{array}$ & $\begin{array}{c}\text { SS } \\
(\mathbf{m g} / \mathbf{L})\end{array}$ & $\begin{array}{c}\mathbf{N H}_{3}-\mathbf{N} \\
(\mathbf{m g} / \mathbf{L})\end{array}$ & $\begin{array}{c}\mathbf{L A S} \\
(\mathbf{m g} / \mathbf{L})\end{array}$ & $\begin{array}{c}\text { Animal oil } \\
(\mathbf{m g} / \mathbf{L})\end{array}$ & PH \\
\hline $\begin{array}{c}\text { Wastewater from preliminary } \\
\text { washing, cleaning and } \\
\text { preliminary rinsing }\end{array}$ & 1200 & 600 & 1000 & 90 & 20 & 40 & $6-9$ \\
$\begin{array}{c}\text { Rinsing wastewater for the 4th } \\
\text { to 7th time }\end{array}$ & 100 & 30 & 60 & 2.0 & 2.5 & 3 & $6-9$ \\
$\begin{array}{c}\text { Washing wastewater (mixed } \\
\text { wastewater) }\end{array}$ & $100-600$ & $50-300$ & $50-300$ & $5-20$ & $1-5$ & $5-20$ & $6-9$ \\
\hline
\end{tabular}

According to the "Emission Standard for Water Pollutants of the Down Industry (GB21901-2008)" [6], the benchmark drainage volume per down product is 60 $\mathrm{m}^{3} / \mathrm{t}$. However, the total water consumption per ton of down products produced by water washing down enterprises is about $350 \mathrm{~m}^{3}$, resulting in $320 \mathrm{~m}^{3}$ of wastewater. The amount of water discharged per unit product far exceeds the baseline. Therefore, the washed down and feather wastewater must be recycled, and it is necessary to improve the reuse rate of water to meet the standard discharge of products. Due to the differences in the raw materials, processes, equipment and management technology used by various enterprises, some enterprises directly discharge the washing wastewater and reused them after treatment; some enterprises separate the primary washing water, washing water and rinsing water according to the water quality, and rinsing water can be reused directly or after simple treatment.

\section{Wastewater treatment model of washed down enterprises in West Anhui}

There are many washed down enterprises in West Anhui, with different scales. Large enterprises are mostly located in economic development zones, and mediumsized small enterprises are mostly located in townships. There are mainly two types of enterprise sewage treatment modes, see Table 2. 
Table 2. Wastewater treatment model of down enterprises in West Anhui

\begin{tabular}{|c|c|c|c|c|}
\hline $\begin{array}{l}\text { Pattern } \\
\text { Name }\end{array}$ & $\begin{array}{l}\text { Enterprise } \\
\text { location }\end{array}$ & Processing mode & Emission mode & $\begin{array}{c}\text { Emission } \\
\text { requirements }\end{array}$ \\
\hline A & $\begin{array}{l}\text { Economic } \\
\text { development } \\
\text { zone }\end{array}$ & $\begin{array}{l}\text { The enterprise has built its own sewage treatment } \\
\text { station, which is discharged into the sewage treatment } \\
\text { plant in the development zone through the municipal } \\
\text { pipe network after pre-treatment }\end{array}$ & $\begin{array}{l}\text { Discharged to the } \\
\text { park sewage } \\
\text { treatment plant } \\
\text { after treatment }\end{array}$ & $\begin{array}{l}\text { Water quality } \\
\text { standard for sewage } \\
\text { discharged into } \\
\text { urban sewers }\end{array}$ \\
\hline B & Township & $\begin{array}{l}\text { The enterprise has built its own sewage treatment } \\
\text { station, after treatment, some of them are reused, and } \\
\text { some of them are directly discharged into the natural } \\
\text { water body }\end{array}$ & $\begin{array}{l}\text { Direct discharge } \\
\text { of enterprises } \\
\text { after treatment }\end{array}$ & $\begin{array}{l}\text { Pollutant discharge } \\
\text { standard for down } \\
\text { industry }\end{array}$ \\
\hline
\end{tabular}

\subsection{Discharge after treatment by the company's self-built sewage treatment station}

The enterprises in towns are relatively scattered, and the enterprises build their own sewage treatment facilities. After the wastewater reaches the "Emission Standard for Pollutants in the Down Industry", it is directly discharged to natural water bodies. In this model, the scale of wastewater treatment of a single enterprise is small, and the company lacks specialized operating personnel. This has resulted in: (1) high construction and operation costs per unit of processing capacity; (2) low level of sewage treatment station operation and greater risk of effluent exceeding standards; (3) environmental protection supervision is difficult

\subsection{Discharged into municipal pipe network after pre-treatment}

For enterprises located in economic development zones, the sewage is discharged to the municipal pipe network after pre-treatment reaches the "Quality Standard for Sewage Discharged into Urban Sewers", and is discharged after being treated by the sewage treatment plant in the development zone.

In this mode, the following problems are likely to occur: (1) If the construction standard of the enterprise's sewage treatment station is low, the treated sewage cannot be reused, the reuse rate is low, and the enterprise consumes excessive water; (2) If the construction standard of the enterprise's sewage treatment station is high, and sewage can be reused, but the small scale of treatment results in (1) high unit construction and operating costs, and (2) a low level of operation due to a lack of professional operating personnel.

\section{Selection of technical route of sewage treatment station in the enterprise}

The requirement of water quality is not high in the process of washing down production, but the process water intake and drainage is large, so it is suitable to treat and reuse the washing wastewater.

According to the survey and practical experience of wastewater reuse and recycling of down enterprises, sensory indicators such as transparency and colour of recycled wastewater affect recycling and reuse. This is because there are many fine hairs in the treated water which are difficult to be treated and separated, resulting in low transparency of reclaimed water.

\section{1 separate drainage and direct reuse}

With the continuous progress of the washing process, the concentration of pollutants in the down wastewater was continuously reduced, and the quality of the wastewater in the last several rinses was better.

The initial washing and cleaning have lower requirements on water quality, and the rinsing wastewater can be directly reused to the initial washing and cleaning processes. The quality of the initial washing and cleaning wastewater is poor. When the rinsing wastewater is directly reused, it is necessary to establish a rinsing wastewater circulation pond. The production process must consider the quality and flow of wastewater, and there are many production pipelines. It needs to be designed and considered in advance in the production process, and it should be implemented in new or technologically modified enterprises.

\subsection{Mixed emissions, reused after treatment}

For the existing enterprises, because of the production process and equipment problems, it is difficult to separate sewage. The mixed wastewater is recycled to the production process after being treated by the enterprise's sewage treatment station. Due to the lack of professional operating personnel in the enterprise's sewage treatment station and low level of management, the sewage treatment process should adopt a process technology route with simple operation and management and low investment ${ }^{[8]}$. According to the characteristics of washed down wastewater, water quality requirements and discharge requirements for recycled water, a threestage treatment process should be used. For the firststage treatment, techniques such as hair removal machine and air flotation should be used to separate feather down in wastewater to reduce the subsequent processing load; because raw poultry may contain poultry manure, the ammonia nitrogen in the effluent is too high. For the secondary treatment, a biological treatment process with a biological nitrogen removal function should be used to remove nitrogen while removing $\mathrm{BOD}$ and $\mathrm{COD}$ in the water; The tertiary treatment uses a process with filtration as its core 
technology to remove fine down and other suspended matter in wastewater.

The process technology route of regulating tank hair dredging machine - air flotation - multistage biological contact oxidation - precipitation - filtration disinfection can be adopted ${ }^{[5]}$. Among them, the regulation tank regulates the unevenness of the water quality and quantity of wastewater; the hair removal machine removes the small down feathers that are not easily settled; the air flotation removes most of the finer feathers, down and other suspended matter; Compared with the biological treatment process of activated sludge process, biological contact oxidation has the characteristics of simple operation, convenient operation, easy maintenance and management, etc; Filtration can use simple-running process technologies such as gravity valveless filters.

\section{3 complete recycling of wastewater}

When all recycling processes (zero discharge process) are adopted for wastewater recycling, electrolyte, surfactant and other substances may gradually accumulate $^{[7,9]}$, which has an adverse impact on feather and down cleaning effect. Compared with the freshwater washing, the variation of oxygen consumption, transparency (turbidity), fluffy and other down washing indexes affects the product grade. Therefore, the wastewater with zero discharge process needs to pay close attention to the change of reuse water quality.

\section{Centralized treatment of industrial clusters}

\section{1 requirements for centralized treatment of industrial cluster}

Down industrial enterprises in West Anhui are mainly located in Lu'an development zone, Chengguan town, Ganchahe town, Guzhen town in Yuan district and Hengshan town in Huoshan county. Among them, Guzhen Town and Shucheng County have formed down feather industry clusters, and the down industry has a dominant advantage locally. The industrial park is the main platform of the local economy, which can promote the industrial agglomeration and trade development in the region ${ }^{[10]}$. As for the foundation of the down industry, the areas where the down industry is the leading industry, such as Guzhen town, Yuan district, Chengguan town, Shucheng county, and Ganchahe town, Shucheng county, can be planned by the government in a unified way, with the government leading the establishment of the down industrial park. According to the Action Plan for Water Pollution Prevention and Control, new and upgraded industrial agglomeration areas should be planned and constructed with centralized sewage treatment facilities.

\subsection{Thoughts on Centralized Processing of Industrial Agglomeration Areas}

\subsubsection{Classification management}

The concentration of pollutants in the initial down washing and washing wastewater is high, while that in the rinsing wastewater is low. Through the planning and construction of down sewage treatment plant in the park, the water washing and down processing enterprises in the park can divide the production wastewater into different parts. After simple treatment, the primary washing wastewater is sent to the down sewage treatment plant for treatment. The high-quality rinsing wastewater can be reused directly. The reclaimed water treated by the sewage treatment plant is reused as the production water of the enterprise. In this way, the construction of centralized sewage treatment plant can replace the construction of scattered sewage treatment stations of each plant, reduce the total investment cost and total operation cost, improve the operation management level of down sewage treatment, and save the investment and management operation cost of enterprises. At the same time, through the guidance of industrial agglomeration, the down industry can expand and strengthen furtherly.

\subsubsection{Environmental stewardship technical services}

It can provide professional technical guidance and services in environmental protection to the management department of the industrial gathering area by employing a third-party professional environmental protection service company as an environmental housekeeper, it can promote the specialization, and intensification of environmental management. It can provide engineering and technical services to sewage enterprises, such as sewage treatment process design, construction or operation of environmental protection facilities, and promote the good construction and operation of environmental protection facilities; provide environmental health examination services and environmental protection training services to industrial parks or environmental protection enterprises, and promote the awareness of environmental safety risk prevention and environmental protection management ability of enterprises.

\section{3 technical requirements for centralized treatment of industrial cluster}

As the wastewater treated by the down sewage treatment plant is directly reused by the down industrial enterprises, and the rest is directly discharged to the natural water body, the treatment standard of the down sewage treatment plant shall meet the class a standard in the discharge standard of pollutants for urban sewage treatment plant. The technology of biological nitrogen and phosphorus removal by activated sludge + advanced treatment should be adopted in the wastewater treatment process. Meanwhile, in view of the characteristics of 
more feathers and small down in the down wastewater, the treatment units of hair catching and air flotation should be added in the primary treatment process.

If there is no special down sewage treatment plant in the industrial cluster area, it is also possible to establish a down sewage treatment plant jointly by multiple manufacturers for the reuse of down production wastewater after treatment, so as to reduce the risk of investment and operation management brought by decentralized construction.

\section{Summary}

West Anhui is an important national base for down industry. In the down industry, a large amount of water needs to be drawn and drained in the process of washing down, and the wastewater from washing down enterprises needs to be recycled. Only by raising the water reuse rate can the unit product standard displacement requirements specified in the discharge standard for down industry water pollutants be met.

Down and feather enterprises should improve the production process, carry out equipment transformation and improve the management level, divert the production wastewater according to the quality, and directly reuse or recycle some of the production wastewater. The threestage treatment process should be adopted according to the characteristics of the wastewater. The first-stage treatment should be adopted. For hair removal machine and air flotation technology, the biological treatment process with biological denitrification function should be adopted for the secondary treatment, and the filtration core technology should be used for the tertiary treatment.

It is advisable to choose the equipment and technology with stable treatment effect and simple operation for the process route of water washing down industrial enterprises. If wastewater recycling technology is adopted, it is necessary to monitor the concentration of electrolyte, surfactant and other components in the recycled water to avoid affecting the quality of down.

In areas such as Guzhen Town, Chengguan Town, Shucheng County of Lu'an City, where the down industry is concentrated and the enterprise is clustered, it is advisable to plan and build an down industrial park and a down professional sewage treatment plant. Through centralized collection and centralized treatment, the company's investment and operation costs are reduced. Industry concentration guides the down industry to become bigger and stronger.

\section{Acknowledgments:}

Key Research Project of West Anhui University (WXZR201720)

\section{References}

1. Thirteenth Five-Year Development Plan for the White Goose Industry in West Anhui, Lu'an City, http: //www.luan.gov.cn/openness/detail/
2. 5837eb297f8b9a9916c12d8e.html (2016)

3. Xia L.Z, Anhui Agricultural Science Bulletin, Discussion on the status quo and development ideas of white goose industry in western Anhui, 23, 17 (2011)

4. Wang Z.C, Anhui University Master Degree Thesis, Research on the Formation Mechanism and Development of Industrial Clusters in Anhui Province (2010)

5. The thirteenth five-year plan for national economic and social development in Lu'an, http: //www.luan.gov.cn/openness/detail/56f0b67ae1b1d1 e0730bafdc.html (2016)

6. Song X.W, Shanxi Construction, Treatment design of washed down industrial wastewater based on recycling and reuse, 42, 20 (2016)

7. China Down Industry Association, Beijing: China Environmental Science Press, Water Pollutant Discharge Standard for Down Industry (GB219012008)

8. Wang Z.Q, Journal of Anhui University of Engineering, Monitoring of the quality of reused water and its effect on the quality of washed down, 32 , (2017)

9. An Q.S, Industrial Water Treatment, Examples of treatment and reuse of down wastewater, 35, 06 (2015)

10. Chen Y.S, Environmental Pollution and Control, Technology and operation examples of complete reuse of down-washed wastewater, 33, 12 (2011) 